sciendo

The Indeterminacy of Translation: Fifty Years Later

Stephen White

Tufts University

Disputatio Vol. 4, No. 32

May 2012

DOI: $10.2478 /$ disp-2012-0005

ISSN: 0873-626X 


\title{
The Indeterminacy of Translation: Fifty Years Later
}

\author{
Stephen White \\ Tufts University \\ BIBLID [0873-626X (2012) 32; pp. 385-393]
}

\begin{abstract}
The paper considers the Quinean heritage of the argument for the indeterminacy of translation. Beyond analyzing Quine's notion of stimulus meaning, the paper discusses two Kripkean argument's against the Quinean claim that dispositions can provide the basis for an account of meaning: the Normativity Argument and the Finiteness Argument. An analogy between Kripke's arguments and Hume's argument for epistemological skepticism about the external world will be drawn. The paper shows that the answer to Kripke's rule-following skepticism is analogous to the answer to Humean skepticism: our use of concepts is more basic than, and presupposed by, the statement of the skeptical problem itself.
\end{abstract}

\section{Keywords}

Indeterminacy of Translation, Kripkean Normativity Argument, Kripkean Finiteness Argument, Humean Skepticism, Naïve Realism.

\section{Quine's argument for indeterminacy}

Quine's argument for the indeterminacy of translation remains a source of fascination and controversy today, fifty years after its publication. The argument is grounded in Quine's conception of the objective facts to which translation is responsible. These, according to him, are strictly limited to those that make up «the overall pattern of associations of sentences with one another and with nonverbal stimulation». (Quine 1960: 27) The significance of the limitations he imposes on the facts to which translation must do justice is apparent in his famous Gavagai example. Suppose that for our informant in the group whose language is to be translated "Gavagai" is prompted by all and only the stimulations that would prompt "There is a rabbit" in us. Both would be prompted, for example, by retinal stimulations caused 
by realistic fake rabbits in plausible surroundings, neither would be prompted by retinal stimulations in the presence of real rabbits that were either completely hidden or well-camouflaged, and so forth. In this case, according to Quine, "Gavagai" construed as a one-word sentence would have the same stimulus meaning as our sentence "There is a rabbit." And for such highly observational sentences, Quine holds that stimulus meaning is a good approximation to meaning as it is intuitively understood. (cf. Quine 1960, 44)

The problem, according to Quine, occurs when we try to equate terms (e.g. referring expressions or predicates) in the language being translated and our own. This is because the stimulus-meaning of "Gavagai" construed as a sentence would be preserved by either of two very different translations. According to the first translation, "gavagai" (construed as a word) corresponds to our word "rabbit." In this case, we can take our informant to mean "is the same rabbit as" when he assents to "gavagai" when we point at the head and when he assents again to "gavagai" when we point at the tail of the same rabbit. According to the second translation, "gavagai" (again construed as a word) corresponds to our "undetached rabbit part." In this case, we suppose that our informant means "belongs to the same rabbit as" when he assents to "gavagai" when we point to the head and again when we point to the tail of the same rabbit. And since Quine thinks that such physical dispositions to respond are the only objective facts there are and that they are exhausted by stimulus-meaning, he holds that translation is indeterminate. (cf. Quine 1960, 51-79)

Quine's examples are never worked out in detail, and there is some skepticism as to whether nontrivial examples of indeterminacy exist. I think, however, that a detailed example can be given based on Quine's thesis that there is no principled distinction between meaning and collateral information (at least where the latter is shared by the community).

"Bachelor" as an Observational Term Example. Imagine an informant - Smith - who applies or withholds the term we are inclined to translate as "bachelor" with complete confidence to people about whom, it seems, he could have no information as to marital status - random strangers in a large city, say. Imagine that two hypotheses occur to us.

Hypothesis (1): Smith uses "bachelor" not with the same meaning we do, but as an observational term to be applied on the basis of an observational gestalt: jaunty step, sharp dresser, air of the bon vivant, etc. 
Hypothesis (2): Smith means what we mean, but thinks he has some clairvoyant insight as to who is and who is not a bachelor.

Can we, as translators, tell which is the correct hypothesis on the basis of the evidence Quine allows? Smith will, of course, make many mistakes if we think of him as applying "bachelor" and very few mistakes if we think of him as applying something like "stereotypical bachelor gestalt." But we can imagine that Smith's behavior in the face of "counterevidence" (marriage records, say) is the same on both hypotheses. He will be indifferent on the first hypothesis because marriage records are irrelevant to the behavioral gestalt. And we can suppose that he will be indifferent on the second hypothesis because he is so confident of his clairvoyant powers that he assumes the counterevidence must be wrong.

Moreover, it seems that all the questions we could ask to determine which hypothesis was correct might be similarly inconclusive. Suppose we ask, "Are you using "bachelor" as an observational term?" Smith might say no even on the hypothesis that he is because the existence of the theory/observation distinction is controversial and he does not believe in it, because he thinks the term is not observational except for people with special powers of observation, etc. Suppose, then, that we ask, "Do you have special powers?" Smith might say yes even on the hypothesis that he is using "bachelor" as on observational term because he thinks as before that his application of the term requires special powers of observation (not clairvoyance). And he might say no, even on the hypothesis that he means by "bachelor" what we mean because he is resolutely modest, thinks everyone is clairvoyant, etc. And - if we imagine trying to teach Smith enough of our philosophy of language, philosophy of science, etc., to allow us to discriminate between the two hypotheses, we might produce such extreme psychological changes that we would have no confidence we weren't changing the meanings of Smith's terms - including "bachelor."

Kripke's arguments that (contrary to what Quine assumes) dispositions cannot provide the basis for an account of meaning

Suppose we start with Kripke's famous example designed to show that what is involved in our following one rule rather 
than another cannot be a matter of our dispositions to respond to new cases.

Plus/Quus Example. Kripke points out that all of our uses of the terms"plus" in the past have involved addends less than some finite number, say N. And he asks what fact about our past usage makes it the case that we were calculating the plus function rather than "quus" defined as follows. For addends both less than N, a quus b = a plus b. Otherwise, a quus b $=5$. (cf. Kripke 1982, 9)

Kripke gives two arguments that dispositions to behave cannot supply the answer.

Normativity Argument. Dispositions do not capture normativity. Dispositions to answer questions etc, are a matter of what we will do, but meaning is a matter of what we should do. (Kripke 1982: 37) This seems to generalize since there has (according to Kripke) to be a fact in virtue of which we meant plus in the past (if we did), and no fact, according to Kripke, could satisfy this normativity requirement. (Kripke 1982: 53; cf.John Mackie's "queer facts" argument in Mackie 1977: 38-42).

Finiteness Argument. We have dispositions to make mistakes, and our dispositions are finite, since our brains are finite. If it is said that we should look at what we would do if we were given more computational capacity, the reply is that this might not extend our dispositions - we might, for example, go insane. (Kripke 1982: 26-27)

This second argument is not impressive as it stands. The possible worlds at which the attempt to augment one's computational capacities has such dramatically destructive results are, it seems, obviously not the relevant ones to look at in characterizing our grasp of the plus function. Of course, they might be the "closest possible worlds" in some sense, and so in some sense definitive of what would happen if we tampered in this way with the brain. For it might simply be the case, possibly even a fact of nature, that trying to tinker with the computational capacities of our brains has destructive results at worlds where the physical laws are like the physical laws at this world. But it seems intuitively clear that if we are appealing to our behavior at possible worlds in order to characterize the concept of addition and what we grasp when we think we grasp the rule associated with it, then the worlds to consider will be those at which such irrelevant mishaps do 
not accompany our attempts to idealize away from our finite limitations.

The problem, then, as Kripke (1982: 28) says explicitly, is really one of circularity. Characterizing the relevant possible worlds requires that we use the notion of addition. For the relevant worlds to look at are the ones at which the steps we take in idealizing away from our finite limitations have no irrelevant effects on our dispositions to respond to new problems in addition. And what is meant by 'irrelevant' in this context? It means, of course, irrelevant to our characterization of the concept of addition in virtue of being detrimental to our ability to add correctly. The relevant possible worlds, then, are the ones that introduce no new or special obstacles to our adding correctly.

\section{Hume's skepticism as an analogue of Kripke's}

There is, I believe, an illuminating analogy between Kripke's argument and Hume's argument for epistemological skepticism about the external world. (Hume 1772: 184) Suppose, as Hume implicitly asks one to do, one focuses on what one is immediately given in one's perceptual experience - an experience, say, as of a room with furniture, other people, and so forth. In such a case, it will be apparent that besides the causal explanation of the experience suggested by common sense (that one is in a room with furniture and other people), there are many alternative explanations. It might be, for example, that one is being misled by an evil demon, that one is a brain in a vat, that one is in a virtual reality setup such as The Matrix, etc. Thus, according to Hume, there is a logical gap between what one is given in perception and any (a posteriori) proposition about the external world - a gap that can only be bridged by an inference. Such an inference, however, could only be a posteriori, since we cannot reason a priori from effects to causes. Thus it could only be justified by some justified belief about the connections between our sense experiences and their causes in the external world. But, to suppose that we have such a justified belief begs the question against the skeptic and flies in the face of the fact that all we can get in principle is more and more perceptual experience. The conclusion is that we can never be rationally justified in preferring any hypothesis about the external causes of our perceptual experience over any other. 
The relevance of Hume's argument to Kripke's discussion of rule following becomes clearer when we see that Hume's argument for epistemological skepticism leads to a version of meaning skepticism. Consider, first, that in order for our words to be meaningful, they must - in addition to being associated with other words - be associated with some extra-linguistic reality to which we have access. On the Humean picture, they would get their meanings through associations with patterns in our perceptual experience. (If I walk around this table, I will see...) But the Humean argument for skepticism about external objects also applies to sense experience. All we are given - all we have access to - are our present experiences (sense-data, including those associated with present memories and anticipations). Thus our words for external objects (tables, chairs, etc.) have no grounding except in our present, actual, solitary, momentary perceptual experiences, and this is too thin a basis to ground meaning.

The conclusion is that there must be some direct perceptions of external objects, since this is the only way to block Hume's argument. This is in effect a transcendental argument in the sense that it is an argument that we can use to counter skepticism by saying that on the skeptic's assumptions, we cannot have a meaningful language. Thus it is one we can use to depict the skeptic as cutting off the branch on which he stands. In this case, the transcendental argument is also an argument for Direct or Naive Realism - the thesis that we are given (we perceive) some external objects directly. That is, it is an argument that sometimes we perceive external objects, and there is nothing else we perceive in virtue of which we perceive them. This blocks Hume's argument because the latter rests on the assumption that there is always a logical gap between what we are given in perception and any a posteriori proposition about the external world. And Naive Realism is the negation of that assumption - that is, it is the thesis that sometimes what we are given in perception has logical implications for a posteriori propositions about the external world. Such experience gives us external objects (conditions, etc.) directly, or, to put it figuratively, "takes us all the way out to the world."

The idea of such direct perception of external objects, then, is clearly an attractive one, epistemologically speaking. (And if the transcendental argument is right, it is one that we must accept.) But we must be able to explain the possibility of the direct perception of external physical objects from different perspectives in order to deal 
with the demonstrative versions of Frege's problem. Consider Evans' (1982: 84) example of such a problem.

Evans' Ship Example. Imagine someone who points out a window to his right at the bow of a ship and says, "That ship was built in Japan." He then points out a window to his left at the stern of a ship and says, "That ship was not." If, contrary to what he assumes, he has pointed to the bow and the stern of the very same ship, then he has said obviously incompatible things of one and the same object.

Such a person is ignorant of a fact, but need not be irrational. Thus we must do justice to the fact that the same ship has been given to him or her from two different perspectives. And we must do so without making the Humean assumption (which as we have seen leads to meaning skepticism) that what we are actually given (what we see) directly are sense-data and that our access to external objects is only indirect.

The explanation I have suggested elsewhere (White 2004) is in terms of basic action possibilities and know how. In such cases we know how to point to the bow of the ship, how to move closer to it for a better look, how to direct someone loading cargo onto the deck of the bow etc. The same is true of the stern. But the ship presents different basic action possibilities from the two perspectives. Such know how, however, does not involve representational intermediaries that could give rise to Humean skepticism. That is, in at least some cases, we are given external object's transparently - not on the basis of any sense-data that we are given more directly. The following case provides an analogy: Sometimes in a brief glance we are given a friend's distress directly - we do not consciously infer it on the basis of anything we are given more directly, such as the geometry of his or her face or posture, much less on the basis of sense-data.

\section{The Response to Kripke and Quine}

On the face of it, though, this does not seem to help with Kripke's problem, since we do not seem to perceive either meanings or mathematical entities like the plus function directly. Direct perception, however, goes with basic actions, and our basic actions are toward the object itself in cases of transparency. We know how to compute the plus function. This know how isn't a fact in Kripke's 
sense - our know how is directed at the plus function itself, so there is no fact which is independent of the plus function and which justifies our going on in a plus-like way.

The case of meaning is somewhat different, because - to put it figuratively - we look through meanings, not at them. That is to say, we manifest our grasp of the meaning in our know how regarding the thing meant or regarding things with the feature meant, etc. For example, we know how to obey the order, "Paint all the fences," as well as the order, "Paint all the white fences." And operating on the basis of color can be a basic action - e.g., stopping on red.

The answer to Kripke's rule-following skepticism, then, is analogous to the answer to Humean skepticism about the external world. In the Humean case the answer is that we cannot coherently adopt the perspective the skeptic requires us to take - since some objects in the external world are given to us directly in perception, we cannot step back from all of our external-world commitments simultaneously and ask how an inference from our sense-experience (our sense-data) to the nature of the external world could be justified. In the case of Kripke's rule-following skepticism, the answer is that we cannot step back from all the things we mean simultaneously in order to ask what fact justifies our moving from the finite number of examples we have actually computed to the plus (as opposed to the quus) function.

As we have seen, one may have no access to the facial geometry of one's distressed friend independently of one's seeing the distress (all one can say on the basis of the brief glance is that the friend was distressed). Analogously, one may have no access to the finite sample on the basis of which one learned a concept - the most that one may be able to say is that one learned to add.

The conclusion, however, is actually stronger than this. For we couldn't possibly describe the finite samples that Kripke talks about independently of our using the concepts Kripke wants to call into doubt. For what right do we have to say that in the past we gave the answer 4 to $2+2$, so any function we were computing must (like plus and quus) give the same result in this case? After all, we gave the answer 4 on a Tuesday, on a day when it rained, when we were in a bad mood, in the past, etc. And there is no reason why a new computation that will necessarily take place in circumstances that are in some respects different has to involve the same answer even for $2+2$.

The point is that our use of concepts is more basic than, and presupposed by, the description of the finite set of examples that is 
presupposed by the statement of the skeptical problem itself. In this it is analogous to the way in which our perception of some ordinary external objects is more basic than, and presupposed by, the description of the sensory experiences that is needed to state the skeptical problem regarding the external world.

$$
\begin{array}{r}
\text { Stephen L. White } \\
\text { Tufts University } \\
\text { Department of Philosophy } \\
02155 \text { - Medford, MA, United States } \\
\text { stephen.white@tufts.edu }
\end{array}
$$

\section{References}

Evans, Gareth. 1982. The Varieties of Reference. Oxford: Oxford University Press.

Hume, David. 1772. An Enquiry concerning Human Understanding. Peru, IL: Open Court, 1988.

Mackie, John. 1977. Ethics: Inventing Right and Wrong. Harmondsworth, Middlesex, England: Penguin Books.

Kripke, Saul. 1982. Wittgenstein on Rules and Private Language. Cambridge, MA: Harvard University Press.

Quine, Willard Van Orman. 1960. Word and Object. Cambridge, MA: The MIT Press.

White, Stephen. 2004. Subjectivity and the Agential Perspective. Naturalism in Question, edited by M. De Caro \& D. Macarthur, Cambridge, MA: Harvard University Press. 